\title{
DEMOCRACIA VERSUS TECNOCRACIA: APATIA E PARTICIPAÇÃO EM SOCIEDADES COMPLEXAS
}

Alessandro Pinzani

O presente artigo pretende discutir a questão da apatia política que, segundo um diagnóstico comum, domina em nossas democracias. Para tanto, confrontaremos dois discursos dominantes com dois discursos antagônicos. Primeiramente, oporemos ao modelo constitucionalista de democracia o modelo de soberania popular. Em segundo lugar, oporemos ao discurso tecnocrático a ideia de uma democracia radical.

\section{0 problema de partida: apatia política nas democracias contemporâneas}

Nos últimos anos formou-se um consenso surpreendente entre muitos autores sobre a crise do sistema democrático. A surpresa deriva do fato de que, depois da Queda do Muro de Berlim, a democracia ocidental parecia triunfar definitiva e incontrastavelmente. De fato, havia tempo que alguns teóricos já tinham alertado para problemas irresolvidos e dilemas que caracterizam nossas sociedades democráticas. Já na década de 1970, Jürgen Habermas e Claus Offe tinham chamado atenção para 
os desafios que o Estado democrático de bem-estar social tinha que enfrentar na Europa (Habermas, [1973] 1980; Offe, [1972] 1984). Com o desenvolvimento da economia capitalista e o multiplicar-se das crises econômicas e financeiras, provocadas - na leitura marxista desses autores - pela própria lógica do sistema capitalista, o Estado se viu na obrigação de encontrar remédios para os efeitos negativos de tais crises e para obviar às correspondentes crises de legitimação que ameaçavam o sistema econômico e político. Um dos instrumentos utilizados para esse fim foi a adoção de políticas de segurança social, que foram aprofundando-se e transformando-se em políticas de bem-estar social. Ora, apesar de considerar esse processo em geral de maneira positiva, Habermas em várias obras alerta para um efeito negativo: o cidadão tende a transformar-se em cliente, renunciando à participação ativa e assumindo a atitude passiva de quem se limita a 136 aguardar serviços do Estado (Habermas, 1973, pp. 9 e ss., 2012, pp. 626 e ss.).

Mais ou menos na mesma época, Niklas Luhmann, ao discutir a noção de "democratização da política", afirmava que as sociedades contemporâneas são tão complexas que as "teorias clássicas da democracia" parecem ultrapassadas e incapazes de entender adequadamente a realidade política (Luhmann, [1965] 1983, p. 153). A ideia de uma vontade popular é inspirada por uma analogia com os indivíduos, mas não se deixa aplicar a sistemas altamente complexos. Essa complexidade faz com que "o nível de informação do público" seja "extremamente baixo". Até em casos que dizem respeito ao interesse pessoal dos cidadãos, como no "do direito tributário, ou daqueles relativos aos seguros e às pensões”, é improvável que o indivíduo conheça as leis em questão. Longe de considerar isso lamentável, Luhmann pensa que "ignorância e apatia são as condições mais importantes para uma mudança das leis, 
que segue passando despercebida, e para a variabilidade do direito e, portanto, são funcionais para o sistema" (Luhmann, [1965] 1983, p. 191).

Como se vê, o diagnóstico de uma crescente apatia política por parte dos cidadãos das democracias avançadas fora formulado, já na década de 1970, a partir de perspectivas diferentes ou até opostas (Habermas lamenta o fato, Luhmann o considera positivo). Nas últimas décadas, esse diagnóstico não foi desmentido, ao contrário, tornou-se um lugar comum na análise sociológica e política. Muitas vezes é utilizado para se lamentar o individualismo que caracterizaria nossas sociedades, como no caso da crítica dos comunitaristas e dos neorrepublicanos ${ }^{1}$, cujos argumentos apresentam uma forte analogia com os dos críticos reacionários ou conservadores à Revolução Francesa (acusada justamente de fomentar esse individualismo dissolvendo os laços sociais tradicionais e isolando os indivíduos, fazendo deles egoístas desenraizados ${ }^{2}$ ).

Não é nossa intenção neste artigo averiguar se o diagnóstico em questão é de fato demonstrado pelas observações empíricas ou se existem fenômenos de engajamento político que o desmintam ao menos parcialmente. Tampouco pretendemos discutir as críticas ao "individualismo" democrático, embora pretendamos voltar a um aspecto delas na seção "O que é soberania popular?". Interessa-nos, antes, pensar acerca de possíveis soluções ao problema da apatia política nas sociedades democráticas, qualquer que seja sua difusão e gravidade.

\footnotetext{
${ }^{1}$ Refiro-me a autores como Michael Sandel, Amitai Etzioni, Philip Pettit e Quentin Skinner.

${ }^{2}$ Uma eficaz reconstrução dessa crítica antirrevolucionária está presente no clássico Hirschman (1991) e, mais recentemente, em Rancière (2005).
} 


\section{É desejável uma maior participação política? ${ }^{3}$}

Poder-se-ia observar que a própria definição de democracia implica a necessidade de tal participação, mas, de fato, não é assim. Sabemos que existem inúmeras definições de democracia e a expressão "governo do povo", que frequentemente é usada como definição, na realidade representa uma tautologia, pois é a mera tradução da

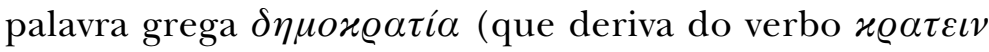
= "governar, dominar" e do substantivo $\delta \eta \mu о \varsigma=$ "povo"). Além disso, essa expressão é ambígua e apresenta, pelo menos, dois problemas.

O primeiro deles: quem é o povo? Habitualmente se pensa que o povo seja constituído por indivíduos que, no momento específico, formam o corpo político dos cidadãos; mas é possível incluir em tal conceito também as gerações passadas e futuras de cidadãos. O povo pode ser pensado, então, nas formas sincrônica ou diacrônica. À primeira 138 perspectiva corresponde um conceito de vontade popular assimilável à volonté de tous mencionada por Rousseau no livro II, capítulo III do Contrato social, isto é, à vontade de todos os indivíduos concretos que formam neste momento o corpo dos cidadãos. À segunda perspectiva corresponde mais o conceito (também rousseauniano) de vontade geral (volonté générale), que transcende as vontades particulares de tais indivíduos. Deparamo-nos aqui com uma visão em paralaxe, na qual o mesmo objeto, se observado por pers-

\footnotetext{
${ }^{3}$ Nosso ponto de partida é oposto ao de Luhmann, naturalmente. Para o sociólogo alemão, uma participação mais ativa não somente é desnecessária: ela sequer é desejável, pois atrapalharia o funcionamento do sistema, ou seja, representaria um fator de instabilidade. Se nossa preocupação for com a estabilidade, portanto, deveríamos ou considerar a participação ativa dos cidadãos como desejável, se ela aumentar a estabilidade do sistema, ou seguir Luhmann e considerá-la inoportuna. Se, ao contrário, partimos da ideia de que a democracia deve ser preferida aos outros sistemas por outras razões que não sua maior estabilidade, devemos nos perguntar se uma participação ativa dos cidadãos nos processos decisórios é necessária ou não.
} 
pectivas diversas, assume contornos e formas diferentes ${ }^{4}$ : ou tomar a perspectiva do Povo com "P" maiúsculo, pensado diacronicamente que vai além daqueles que são os cidadãos atuais; ou a do povo, com "p" minúsculo, pensado sincronicamente. A dificuldade em assumir a primeira perspectiva consiste na quase impossibilidade de definir a vontade popular ou geral. O Povo se tornaria uma entidade quase mística; sua vontade, algo a ser atingido por uma espécie de iluminação, ao se escutar a voz da própria consciência, como afirma Rousseau no livro IV, capítulo I do Contrato Social, ou, ainda pior, uma vontade que só alguns poucos podem conhecer e impor aos demais. $\mathrm{O}$ risco da segunda perspectiva (a do povo pensado sincronicamente) é, notavelmente, o de uma tirania da maioria. Se o povo "sincrônico" decidisse discriminar alguns cidadãos, não haveria razão para negar-lhe esse poder - a não ser a existência de direitos individuais subtraídos ao arbítrio dele. Assim, chegaríamos ao conflito entre direito e política, entre Poder Judiciário e Poder Legislativo, entre direitos individuais e soberania popular. Cabe salientar que ambos os conceitos (mas especialmente o diacrônico, por razões óbvias) tendem a fazer do povo um indivíduo dotado de uma vontade única, seja esta última pensada como vontade geral ou como vontade de todos, como unanimidade ou como vontade de uma maioria. Rousseau e a maioria dos pensadores modernos acreditam ser possível falar em um povo, no povo, como se este fosse algo unitário e compacto. Veremos na seção "Democracia radical" que esse conceito está longe de ser óbvio.

O segundo problema implicado na ideia de um governo do povo diz respeito às formas em que tal governo é realizado concretamente. De que maneira o povo exerce seu poder? Em outras palavras: como se manifesta a soberania

${ }^{4} \mathrm{O}$ conceito de visão em paralaxe aplicado à filosofia é utilizado por Žižek (2008). 
popular? Como se vê, trata-se de uma questão essencial para responder à questão da participação popular, pois corresponde a perguntar-se em que consiste concretamente tal participação. Respondendo a esse segundo problema, portanto, teríamos dado um passo importante em relação à questão central que nos ocupa aqui.

\section{0 que é soberania popular?}

Em seu recente livro Über Volkssouveränität [Sobre a soberania popular], Ingeborg Maus critica a práxis de substituir a formação democrática da vontade popular pelo recurso aos tribunais, em particular, ao tribunal constitucional (Maus, 2011, p. 27 et passim). A autora lembra que as teorias democráticas do século XVIII insistiam na ideia de que a vontade soberana do povo deveria expressar-se livremente em uma ação continuada de legislação, enquanto as instituições criadas pela Constituição só revestiriam o papel secundário

140 (embora necessário) de implementar tal vontade por meio de atos de governo e sentenças jurídicas. Essa ideia, ainda dominante em Rousseau e em Kant, assim como na teoria e na práxis dos revolucionários franceses, é substituída nos Estados Unidos dos founding fathers pela concepção segundo a qual o ato constituinte, no qual o povo exerce diretamente sua soberania, é único: uma vez criada a Constituição, o poder constituinte passaria ao tribunal constitucional, que avocaria para si o poder de interpretar a vontade soberana, inclusive em ocasião de modificações à própria Constituição (como acontece no Brasil). Em vez de limitar-se a verificar a conformidade formal das leis emitidas pelo Parlamento, o tribunal constitucional assume um papel de colegislador, ou impondo ao Parlamento determinada interpretação das normas constitucionais e dos valores nelas refletidos, ou decidindo diretamente sobre questões concretas em lugar do Parlamento. Dessa maneira, diz a autora, referindo-se à situação alemã com argumentos que, contudo, poderiam 
ser aplicados também ao Brasil, "o Tribunal Federal Constitucional [Bundesverfassungsgericht] trata a lei fundamental [Grundgesetz, isto é, a Constituição alemã] como se fosse um código de direito civil formulado de maneira ambígua" (Maus, 2011, p. 47). Por isso, começa a decidir sobre questões pontuais como a composição dos órgãos decisórios das universidades, assumindo, de fato, funções legislativas.

Segundo Maus (2011, p. 48 e ss.), há duas maneiras de pensar a Constituição. A primeira é dominada pela ideia (originária em Montesquieu) do controle recíproco dos poderes e da distinção entre estes, sem que haja, contudo, uma separação das competências, de modo que um poder pode interferir nas competências de outro para controlá-lo, como quando o tribunal constitucional anula uma lei do Parlamento em nome de diferente interpretação de certa norma constitucional. Esse modelo, que Maus chama de constitucionalista, é compartilhado pelos pensadores norte-americanos anteriormente mencionados. Eles veem na existência do poder político o problema principal e nos direitos individuais somente instrumentos para controlar tal poder. Daí uma visão negativa das liberdades: elas definem os limites que o poder político não pode ultrapassar sem cair no abuso ${ }^{5}$. No segundo modelo, o da soberania popular, as liberdades são vistas, em primeiro lugar, como instrumento que garante a participação do indivíduo no processo decisório. Nesse modelo, à separação dos poderes corresponde uma separação das competências: só o Legislativo tem a faculdade de fazer leis, enquanto o Executivo e o Judiciário se limitam a implementá-las.

\footnotetext{
${ }^{5}$ Maus (2011, p. 52) lembra que, no caso da Constituição estadunidense, os direitos individuais não são enunciados no próprio corpo do texto originário, mas são garantidos por uma emenda constitucional (a primeira) que foi introduzida por iniciativa dos chamados antifederalistas, que eram contrários à aprovação da nova Constituição de 1788 em substituição dos antigos Artigos da Confederação, de 1777.
} 
Maus explica o triunfo do primeiro modelo em anos recentes apontando para a crescente complexidade da sociedade, que faz com que seja difícil entender em que lugares e por quais atores são tomadas as decisões relevantes, tais como, por exemplo, as que regem a vida econômica. Dessa forma, a própria ideia de participação perderia sentido e os indivíduos prefeririam servir-se de seus direitos para garantir um espaço de isenção da ação do Estado, em vez de usá-los para influenciá-la diretamente. Isso leva a atribuir um peso sempre crescente ao Poder Judiciário e a ampliar o conceito de Constituição, conferindo à carta fundamental o papel de elencar objetivos materiais que devem ser realizados independentemente da ação do Legislativo: quando este não o fizesse, caberia aos tribunais impor tal realização. Destarte, a própria noção de direito acaba mudando seu sentido, pois o direito passa assim a regulamentar "a normalidade do comportamento social”, enquanto sua tare-

142 fa deveria ser a de regulamentar "a anormalidade de um conflito pontual, no qual os indivíduos, não representáveis, se confrontam como partes num processo civil ou são isolados literalmente como réus num processo penal" (Maus, 2011, p. 59 e ss.). Longe de entrar em ação nessas situações "anormais", o direito acaba por oferecer os critérios com base nos quais organizamos nossa vida cotidiana, substituindo assim as normas sociais.

Essa tendência já foi descrita por inúmeros autores, frequentemente com o nome de juridificação ou judicialização, mas uma das análises mais interessantes foi feita por Axel Honneth em seu livro mais recente, Das Recht der Freiheit [O direito da liberdade], no qual o autor, ao analisar a liberdade jurídica como uma das diferentes formas de exercício da liberdade individual, afirma que nela estaria presente o risco de uma patologia social, a saber: a total identificação, pelos indivíduos, de sua liberdade com a liberdade jurídica, isto é, com seus direitos negativos, fazen- 
do com que tais direitos acabem tornando-se os elementos constitutivos do plano de vida de seus titulares. Assim, os sujeitos tendem a "retirar-se para a gaiola de seus direitos subjetivos e a pôr-se perante os outros exclusivamente como pessoas jurídicas", demandando a resolução de todos os seus conflitos unicamente aos tribunais. A pessoa se reduz assim à "soma de suas pretensões jurídicas" (Honneth, 2011, pp. 161, 164), fechando-se ao fluxo comunicativo que a une às outras pessoas. Os direitos são usados, portanto, como uma barreira às exigências de justificação que provêm dos outros indivíduos. Isso, por um lado, protege os indivíduos da tirania ética da comunidade na qual vivem, mas, por outro, os isola dos outros membros de tal comunidade, que passam a ser vistos como meros obstáculos à própria liberdade individual. Mais uma vez, assistimos à tendência de os cidadãos se fecharem em sua esfera privada, considerando sua liberdade somente no sentido negativo de uma proteção da ingerência alheia (in primis por parte do Estado), e não no sentido positivo da possibilidade de participar ativamente no processo decisório democrático. Tal participação pressupõe, segundo Honneth (2011, pp. 219 e ss.), que os indivíduos concebam sua liberdade como liberdade social, ou seja, como algo que só pode ser exercido em conjunto com outros indivíduos e que só se realiza na dimensão comunitária ou social. Experimentamos nossa liberdade individual somente no contexto de obrigações sociais que surgem do fato de desempenharmos certos papéis sociais (por exemplo, enquanto parceiros, pais, amigos, agentes econômicos, produtores, consumidores, cidadãos etc.) . Essa liberdade é social, pois, longe de isolar o indivíduo do contexto social no qual se encontra, só é vivida em tal contexto, isto é, na interação com outros indivíduos. O modelo constituinte ameaça obscurecer essa dimensão social da liberdade individual, reduzindo-a à mera defesa de uma esfera privada subtraída ao poder estatal e deixando que 
este último se controle autonomamente por meio de mecanismos de checks and balances (quase em analogia ao modelo sistêmico de Luhmann). O modelo da soberania popular, pelo contrário, torna explícito em que sentido a liberdade individual só pode ser exercida no contexto social da participação no processo decisório.

Em consequência do exposto anteriormente, o primeiro ponto sobre o qual construir a resposta à questão da participação política nas democracias contemporâneas é o de que não há democracia sem exercício concreto da soberania popular e que este se dá em forma de atividade legislativa continuada, não somente no exercício pontual do poder constituinte. Em segundo lugar, se quisermos repensar a participação democrática, particularmente em vista a um aprofundamento da democracia em nossa sociedade, seria necessário primeiramente resgatar essa dimensão social da liberdade individual, que é justamente a primeira vítima da 144 mencionada judicialização ou juridificação, isto é, enfim, do modelo constitucionalista. Em outras palavras, seria necessário fortalecer as formas de participação direta no processo decisório. Ao mesmo tempo, contudo, não devemos pensar que a participação cidadã se esgote em atos como o de votar em uma eleição ou referendo. Há outras formas de participação democrática que devemos agora considerar.

\section{Desconfiança democrática e ativismo cidadão}

Rosanvallon (2006) identifica um problema que considera característico de toda democracia real: a dissociação entre legitimidade e confiança. Em outros termos, os cidadãos reconhecem a legitimidade das principais instâncias de decisão democrática (parlamentos, governos, partidos, administrações públicas, tribunais etc.), mas não confiam nelas, ou melhor, desconfiam que abusem do poder que lhes é democrática e legitimamente atribuído. Segundo Rosanvallon, essa desconfiança não é um fenômeno novo 
ou típico das democracias contemporâneas, mas pertence à própria democracia desde seu nascimento e se exerce de três formas: como ação de vigiar (surveillance), como impeachment e como questionamento de juízos (políticos e jurídicos). Não se trata de formas institucionais de exercício da desconfiança, embora não tenham faltado tentativas de institucionalizá-las, como, por exemplo, no plano de Constituição elaborado por Condorcet [no prelo]. Por isso, o termo "contrademocracia", utilizado por Rosanvallon para designar essas três formas de controle, não aponta para o eventual caráter antidemocrático das mesmas, mas indica “a forma de democracia que contraria a outra, a democracia dos poderes indiretos disseminados no corpo social, a democracia da desconfiança organizada oposta à democracia da legitimidade eleitoral” (Rosanvallon, 2006, p. 16). Sob essa perspectiva, o povo não se limita a escolher seus representantes por meio de eleições ou, onde isso esteja previsto, a participar diretamente de escolhas por meio de plebiscitos, referendos e iniciativas populares; ele efetua uma atividade continuada de controle não só sobre os governantes eleitos, mas também sobre os técnicos não eleitos tais como juízes, funcionários públicos etc. $\mathrm{O}$ povo exerce, assim, o que pode ser chamado de "soberania social negativa" no contexto daquela que, por sua vez, pode ser denominada, além de contrademocracia, de "democracia negativa" (Rosanvallon, 2006, p. 21); de democracia da recusa (démocratie de rejet) enquanto oposta à democracia de projeto (démocratie de projet), já que o poder de veto do povo (isto é, o poder de rechaçar políticas públicas ou homens políticos) prevalece sobre a capacidade dos estadistas de ganhar a confiança dos eleitores por meio de suas propostas; de "democracia de imputação" (na qual os governantes estão sob contínua ameaça de serem chamados a responder juridicamente por suas ações) enquanto oposta à "democracia de confrontação” (na qual a luta política não acontecia nos tribunais ou 
por meio de acusações recíprocas de improbidade e corrupção, mas pela oposição de diferentes visões políticas). Rosanvallon ainda tenta mostrar como nenhuma dessas diferentes faces da democracia é completamente nova e defende a ideia de que nelas o povo demonstra uma "presença ativa e permanente" (2006, p. 37). Nosso autor cita um manifesto de 1790 elaborado pelo Cercle Social (um círculo político ao qual pertenciam, entre outros, Brissot e o próprio Condorcet), no qual se afirma: "O poder de vigiar e de expressar sua opinião (o quarto poder, o da censura, do qual não se fala nunca), enquanto pertence a cada indivíduo e enquanto cada indivíduo o pode exercer por si, sem representação e sem perigo para o corpo político, constitui de maneira essencial a soberania nacional" (apud Rosanvallon, 2006, p. 44). Como se vê, estamos além da tradicional oposição entre pouvoir constituant e pouvoir constitué, pela qual a soberania popular se exerce plenamente no ato consti146 tuinte e, depois, somente de forma irregular (nas emendas constitucionais submetidas a referendo) ou indireta (por meio dos tribunais constitucionais, por exemplo). Na visão da democracia negativa ou contrademocracia, a soberania segue, ao contrário, sendo exercida diretamente pelo povo em formas não institucionais, isto é, não pertencentes ao âmbito do poder constituído, mas estritamente políticas.

Contudo, essas formas de controle direto não são isentas de riscos. Colin Crouch (2004) aponta para um deles em particular, ao distinguir duas formas de ativismo dos cidadãos. Há uma "cidadania positiva" que visa desenvolver "identidades coletivas", definir seus interesses e, baseando-se nestes, formular exigências ${ }^{6}$; e há um "ativismo negativo" que se limita a acusar e a lamentar-se, que tem como fim principal o de exigir prestação de contas aos políticos. Segundo Crouch, "a democracia precisa de ambas aproximações à cidadania, mas

${ }^{6}$ Exemplos de tal ativismo "por baixo" são descritos em Chatterjee (2004). 
no momento presente a negativa está recebendo uma ênfase consideravelmente maior" (2004, p. 13). No modelo negativo, a política segue sendo exclusividade das elites, embora estas possam ser "acusadas e culpadas por uma multidão raivosa de espectadores, quando se descobre que fizeram algo errado" (Crouch, 2004, p. 14). Essa raiva pode levar, porém, ao cinismo e à desilusão em relação à política e à própria democracia - algo muito diferente da desconfiança democrática de Rosanvallon. Crouch lamenta, nesse contexto, uma "degradação da comunicação política de massa" (2004, p. 26), marcada por vários fenômenos: a crescente personalização da política eleitoral (vota-se na pessoa e não no partido ou em certo projeto de sociedade); o sensacionalismo da mídia (interessada em descobrir escândalos para aumentar seus lucros em termos de cópias vendidas ou de espaços publicitários, mais do que para exercer a função de vigilante da transparência); a crescente complexidade do mundo, em particular da economia, que torna quase impossível aos cidadãos identificar claramente seus interesses e formular seus pedidos à classe política, que, por sua vez, parece incapaz de uma gestão eficaz da realidade. Por essa razão é muito mais simples, para os políticos, "promoverem imagens de sua integridade e retidão", para seus opositores, pesquisar "suas vidas privadas para encontrar evidências do contrário" e para os cidadãos permanecerem simples espectadores, prontos a indignar-se quando tais provas forem exibidas (Crouch, 2004, p. 28). Não somente a participação democrática é reduzida ao momento eleitoral, pela incapacidade de os cidadãos se organizarem de maneira "positiva" para exigir políticas ligadas aos próprios interesses, como também a competição eleitoral "assume a forma de uma busca de indivíduos dotados de caráter e integridade" (Crouch, 2004, p. 28), como se isso em si fosse garantia de bom governo. Essa atitude não leva em conta dois aspectos fundamentais. O primeiro é a não transparência dos mecanismos econômicos impessoais 
que operam na vida de uma sociedade. Constatar tal caráter não transparente e impessoal não significa, contudo, afirmar a inevitabilidade da ação desses mecanismos. Por mais obscuros que sejam, eles representam a consequência de determinadas escolhas políticas, como, por exemplo, a liberalização do mercado financeiro, as privatizações dos anos de 1980 e das décadas seguintes, a criação da OMC etc. O segundo aspecto diz respeito ao fato de que, em muitos casos, o poder segue sendo exercido de forma não transparente por atores que são capazes de impor sua agenda aos governos e, ao mesmo tempo, permanecem nos bastidores, imunes ao escrutínio do público. A transparência que o cidadão exige dos representantes eleitos não é exigida em igual medida dos representantes dos lobbies, dos executivos de empresas e grupos econômicos, dos banqueiros ou dos donos dos meios de comunicação de massa. Em outras palavras, a desconfiança democrática que anima o modelo da contrademocracia pode 148 rapidamente transformar-se na postura negativa que caracteriza, segundo Crouch, a pós-democracia, a saber: cinismo e desilusão com a política; atitude passiva de simples indignação; renúncia à capacidade de influenciar ativamente o processo democrático, que o relega, assim, à influência de outros atores, mais organizados, e que transforma a democracia, de fato, em oligarquia.

Um dos desafios centrais com o qual nossas democracias hoje se deparam consiste em encontrar equilíbrio entre as legítimas exigências de transparência e controle da contrademocracia, por um lado, e a consciência de que existem formas de exercer o poder que, por sua natureza, tendem a permanecer opacas e a escapar ao controle democrático, por outro. As forças que se servem de tais formas aumentam seu poder justamente à medida que, desviando a opinião pública de suas manobras e de seus interesses, conseguem debruçá-la sobre escândalos dos políticos. Nisso são ajudadas muitas vezes por uma mídia cúmplice ou cointeressada, 
que considera seu dever vigiar a moralidade dos políticos, mas não os negócios e as atividades de empresas, bancos, grupos financeiros etc. E frequentemente são ajudadas também por elementos do próprio sistema institucional que, por várias razões e às vezes de boa fé, acabam solapando totalmente a confiança nas instituições democráticas, contribuindo assim para que os cidadãos identifiquem o grau de legitimidade democrática de um governo com o grau de moralidade pessoal de seus membros. Isso não significa, naturalmente, justificar a corrupção ou endossar o ditado, tristemente popular no Brasil, "rouba, mas faz". Como vimos anteriormente, controlar a ação dos políticos e chamá-los a responder por seus atos é uma forma fundamental de exercer a soberania popular já que o caráter democrático de nossas sociedades é assegurado por formas não institucionais de exercício da soberania. Tais formas, contudo, não deveriam limitar-se ao controle dos governantes pelos governados, mas estender-se a todas as formas de poder, em especial as que se prestam ao abuso e que ameaçam esvaziar o sentido da própria participação democrática, uma vez que são exercidas de maneira opaca e são subtraídas ao escrutínio dos cidadãos.

Por outro lado, como já observamos, em sociedades complexas como a nossa, operam mecanismos impessoais que são dificilmente controláveis pelas instituições democráticas, cujo funcionamento permanece obscuro até para os indivíduos neles envolvidos. Não é necessário seguir aqui Luhmann ou o próprio Habermas e falar de sistemas autopoiéticos, que se tornaram autônomos uns em relação aos outros, portanto, também em relação à esfera da política e, sobretudo, ao mundo da vida dos indivíduos que pertencem a uma sociedade ${ }^{7}$; é suficiente constatar que as interco-

\footnotetext{
${ }^{7}$ Este é um tema que perpassa a obra habermasiana desde os anos de 1970. Ver particularmente Habermas (2012, p. 205 e ss.).
} 
nexões e as influências recíprocas que caracterizam nosso mundo "globalizado" e, em particular, a economia globalizada atingiram um nível de complexidade que as tornam praticamente incompreensíveis, até na reconstrução ex post de acontecimentos como a crise de 2008 - da qual foram dadas as explicações mais divergentes. Nesse sentido, ao preocuparmo-nos com as consequências do "ativismo negativo", não podemos cair no erro (simétrico àquele de quem se indigna com os políticos) de atribuir a culpa dos problemas que assombram nossa sociedade exclusivamente aos sujeitos econômicos mais poderosos. Tal erro foi cometido, por exemplo, por boa parte da mídia estadunidense, que preferiu culpar os banqueiros e sua ganância pela crise econômica de 2008, ao invés de identificar as causas sistêmicas que levaram a ela. Ora, refletir sobre essas causas não é tarefa fácil para economistas profissionais, muito menos para cidadãos comuns. Isso parece sugerir que esses pro150 blemas com os quais se deparam nossas democracias sejam complexos demais para serem resolvidos democraticamente, isto é, por meio da participação ativa dos cidadãos. Tal impressão é, contudo, profundamente equivocada. Os problemas em questão não são de natureza meramente técnica e exigem respostas políticas. As medidas tomadas para combater a crise econômica atual são quase todas medidas políticas, ainda que sejam apresentadas como medidas técnicas. Tanto a escolha entre austeridade e investimento público, quanto aquela entre cortes nas despesas estatais e aumento da pressão fiscal sobre os cidadãos mais ricos, tratam-se de escolhas políticas que pressupõem não apenas o conhecimento de dados macroeconômicos, mas também certa visão da sociedade e certos conceitos de justiça social. Ora, esses elementos são precisamente aqueles que deveriam ser objeto do escrutínio popular: os cidadãos devem poder escolher entre diferentes visões da sociedade e os candidatos a governá-los deveriam explicitar qual é a sua, ao invés de 
esconder-se atrás da personalidade de seus líderes ou dos defeitos pessoais dos adversários. A escolha entre visões e valores políticos diversos é mais relevante do que a escolha entre indivíduos dotados de características diferentes.

Diante do exposto, o terceiro ponto da nossa resposta à questão da participação política diz respeito ao fato de que tal participação se dá de várias formas além daquelas institucionais previstas na Constituição, mas pode rapidamente degenerar em atitudes negativas de cinismo, desilusão, moralismo cego etc. Para evitar isso, seria necessário manter viva nos cidadãos a consciência de que eles, apesar da existência de mecanismos não transparentes e impessoais, podem contribuir para decidir os destinos de sua sociedade através de escolhas políticas concretas. Há uma série de fatores que, porém, dificultam essa tomada de consciência, quer do ponto de vista objetivo de representar obstáculos à implementação da vontade popular, quer do ponto de vista subjetivo de desmotivar a participação ativa dos cidadãos. $\mathrm{O}$ primeiro é a mencionada presença de mecanismos impessoais que parecem obedecer a uma lógica própria, independente de qualquer tentativa de controle político. Trata-se da tendência a naturalizar tais mecanismos e os fenômenos que deles se originam. O segundo fator consiste na ideia, derivada de tal naturalização, de que a política se reduz à mera administração do existente, visando minimizar os efeitos negativos de fenômenos socioeconômicos naturalizados. Disso nasce o discurso tecnocrático, que consideraremos na próxima seção. Um terceiro fator é o interesse de determinados sujeitos sociais a minimizar a participação popular. Não é novidade que também nas sociedades mais democráticas existem grupos ou indivíduos que tentam utilizar o poder político para perseguir seus interesses particulares. As estratégias utilizadas por tais sujeitos consistem justamente em defender a mencionada naturalização dos fenômenos socioeconômicos e em servir-se do discurso tec- 
nocrático, que nega qualquer valor à participação democrática. Por fim, há um quarto fator que diz respeito mais à teoria da democracia do que à práxis democrática concreta: a ideia de que a política deve basear-se no consenso ou ter este como seu fim. Já que todos esses fatores estão entrelaçados, nas próximas seções os tratarei sem muitas distinções, começando por uma análise do discurso tecnocrático que, a meu ver, representa o maior obstáculo à democratização de nossa sociedade por ser compartilhado não somente por quase todos os políticos, mas também por boa parte dos cidadãos comuns (contrariamente a teorias tais como a de Luhmann, que são excessivamente complexas).

\section{A produção do discurso tecnocrático}

No ano de 1976, portanto oito anos depois do movimento estudantil de 1968, foi publicado na revista Actes de la Recherche en Sciences Sociales um estudo que teve grande repercussão

152 e que, apesar de ser assinado por Pierre Bourdieu e Luc Boltanski, era o resultado de um trabalho de grupo, como o próprio Boltanski (2008) salientou. O estudo, cujo título era "La production de l'idéologie dominante" consistia em uma análise de diferentes textos que compartilhavam uma mesma ideia de fundo: a de que a política, em particular a política econômica, seria uma espécie de ciência que pode ser exercida unicamente por experts, já que somente eles conhecem as leis que regulamentam a vida da sociedade e seu sistema econômico (Bourdieu e Boltanski, 1976).

As fontes, nas quais se baseia aquela pesquisa, são de natureza variada: publicações acadêmicas, discursos de políticos, entrevistas com estadistas e experts, pesquisas de opinião, artigos de periódicos e de revistas, mas também manuais usados em institutos de formação da elite político-econômica como o Institut d'Études Politiques (IEP), conhecido também como Science Po, e o Institut National de la Statistique et des Études Économiques (INSEE). Os 
autores pretendem mostrar, a partir desses textos, a existência de um discurso anônimo (é impossível determinar sua origem ou quem o utilizou primeiro), que se desenvolveu até tomar forma de uma verdadeira ideologia dominante. Mas o que entendem os autores por "ideologia"? E o que seria uma "ideologia dominante"?

O termo "ideologia" deve ser entendido, em primeiro lugar, em sentido neutro: como expressão de uma visão da sociedade que se compõe de uma pluralidade de elementos heterogêneos entre si, os quais, contudo, formam um conjunto coerente. Dessa forma, entre esses elementos há uma determinada concepção de ciência, uma determinada teoria do agir humano, uma determinada doutrina do Estado e, sobretudo, um sistema de valores e de finalidades sociais principais que não apenas não são questionados, mas também, na verdade, considerados inquestionáveis, como, por exemplo: crescimento econômico ilimitado, estabilidade financeira, aumento constante do PIB etc. Trata-se da ideologia da classe dominante em duplo sentido: de ideologia da classe dominante in primis, torna-se também o discurso mais influente ou até o mais utilizado no interior da própria sociedade (na mídia, na academia, na política etc.). Para obter uma aceitação desse tipo, contudo, deve "demonstrar" ser neutra, isto é, não ser uma ideologia no sentido mais restrito do termo (ou seja, uma visão da sociedade que possui um viés específico e é, por definição, parcial e não objetiva). Esse discurso deve apresentar-se como representação sóbria, objetiva, até científica do mundo social, que se eleva acima dos cotidianos conflitos ideológicos e políticos. Por simplicidade, em seguida, utilizarei o termo "ideologia dominante" também quando não me referir ao ensaio de Bourdieu e Boltanski, embora me pareça que simplifique excessivamente algo muito mais complexo.

Antes de prosseguir na análise da pesquisa feita pelos dois autores franceses, gostaria de responder de antemão a 
algumas possíveis objeções. A primeira diz respeito ao fato de que a ideia de classe dominante pode parecer obsoleta nos dias de hoje. Contudo, essa impressão poderia ser interpretada justamente como uma prova de que o discurso dominante segue cumprindo sua função. Ele nega, nesse caso, não simplesmente a existência da luta de classe nos moldes do marxismo tradicional, mas antes a própria existência das classes sociais. Destarte, é negada também a existência de conflitos em sentido próprio. As tensões sociais são descritas como resultado a se lastimar de uma série de atitudes erradas: ignorância das verdadeiras leis sociais, más interpretações da situação social e posições ideológicas (no sentido de visões não científicas e parciais). A “ideologia dominante" apresenta a sociedade como uma totalidade relativamente homogênea, na qual é possível harmonizar os interesses divergentes entre si que, inegavelmente, estão presentes nela. Há divergência de opiniões somente sobre a questão da melhor manei-

154 ra para chegar a essa harmonização: se por meio da sábia direção de um governo de experts ou da plena liberdade aos interesses, na convicção de que o equilíbrio resultará deste livre-jogo de opostos (não podemos cometer o erro de confundir a ideologia expertocrática ou tecnocrática com outra ideologia, a neoliberal: apesar de possuirem algo em comum, e de ambas poderem ser chamadas de dominantes, elas se distinguem à medida que os tecnocratas confiam na ação dirigente das instituições estatais e os neoliberais na capacidade autoreguladora do livre-mercado).

Para seu estudo, Bourdieu e Boltanski reuniram uma coletânea de definições, afirmações e declarações que possuem natureza ideológica (tomada em sentido neutro, a saber, como expressão de uma visão complexa e coerente da sociedade entre as várias visões possíveis), mas que são apresentadas pelos indivíduos ou pelos textos que as formulam como sendo obviedades triviais, constatações objetivas, resultados científicos ou pura e simplesmente expressões da 
única verdade. A essa coleção eles deram, inspirando-se no Dicionário das ideias feitas de Flaubert, o título de "Enciclopédia das ideias feitas e dos lugares comuns usados nos lugares neutros" (Bourdieu e Boltanski, 1976, p. 9 e ss.). Nela estão presentes pensadores e políticos que pertencem às mais diferentes correntes: de esquerda e de direita, conservadores e progressistas. Em seguida, apresentaremos quatro exemplos (dos mais de cem itens que compõem a coleção), que me parecem particularmente relevantes para nosso assunto.

No item "Cooperação" é citada a seguinte declaração de Louis Armand": "Este tipo de trabalho, que eleva o espírito (como dizia Saint-Exupéry: 'Façam com que eles construam uma catedral e eles se amarão'), é completamente diferente do trabalho de negociação - antes, é praticamente o seu contrário" (apud Bourdieu e Boltanski, 1976, p. 15). Em outras palavras: as negociações entre interesses divergentes de diferentes grupos sociais são uma atividade que avilta o espírito e ameaça a coesão social. A vida social deveria antes ser vista como a cooperação espiritual e comunitária entre parceiros sociais.

No item "Ideologia" é citado, entre outros, Michel Poniatowski, que foi várias vezes ministro: "As ideologias que se apresentam como contemporâneas - o marxismo, o socialismo, o capitalismo, o liberalismo etc. - são superadas pela civilização que está se desenvolvendo perante nossos olhos" (apud Bourdieu e Boltanski, 1976, p. 21). É notável que o capitalismo seja definido aqui como uma ideologia. Destarte, não se nega que a sociedade contemporânea seja capitalista; ela se situa, antes, acima de qualquer ideologia e se encontra num processo de transformação que deixa parecer anacrônicas e inadequadas todas as ideologias. Quem a denomina de capitalista não somente se serve de um concei-

\footnotetext{
${ }^{8}$ Engenheiro, primeiro presidente da Comunidade Atômica Europeia (Euratom) e membro da Académie Française.
} 
to ideológico (no sentido "ruim" do termo), mas demonstra que seu pensamento é completamente inatual e obsoleto.

No item "Informação" é citado o célebre economista Jean Fourastié:

"De fato é preciso convencer as pessoas a fazer algo, mas isso [deveria ser feito] somente apresentando-lhes a situação, ou seja, fazendo que tomem consciência da realidade, e não por meio de regras. Não se trata de obrigar as pessoas a agir, mas de informá-las sobre certa realidade, de levá-las à constatação de que está no seu interesse, na sua natureza, agir conforme certas linhas de ação e conforme certos métodos" (apud Bourdieu e Boltanski, 1976, p. 23).

Em outras palavras: trata-se de abrir os olhos das pessoas para a realidade, para que tomem consciência dela. Essa obra de esclarecimento deveria ser realizada 156 pelo expert, que informa as pessoas simples quais são os verdadeiros interesses delas e quais os métodos certos para persegui-los.

Por fim, e ainda mais relevante para nossa discussão, no item "Parlamentarismo" é citado o texto de uma questão da prova de admissão à escola de elite École Nationale d'Administration (ENA) do ano 1966: "O parlamentarismo, em cujo centro está a assembleia popular, parece não ser mais adequado às necessidades do mundo hodierno" (apud Bourdieu e Boltanski, 1976, p. 26). O parlamentarismo representaria uma visão obsoleta do mundo, segundo a qual a política tem a ver com a barganha entre interesses divergentes e a busca de acordos. Os tecnocratas da ENA criticam o parlamentarismo em nome de uma forma mais eficiente de governo, a saber, em nome do governo dos especialistas, que não precisa submeter-se a negociações desgastantes que custam tempo e energia, mas pode tomar suas decisões conforme critérios científicos objetivos. 
Esse último ponto é decisivo. Para Bourdieu e Boltanski (1976), a ideologia dominante é produzida em lugares que se apresentam como neutros - universidades, institutos de pesquisa, mídia - que dão a ela o aspecto de ser científica e imparcial, o qual deveria negar o caráter ideológico do saber produzido em tais lugares. Destarte, o expert, em seus vários avatares (cientista político, jurista, economista, cientista social, especialista em estatística etc.), se torna o protótipo do sábio imparcial, que se situa acima dos conflitos cotidianos e cuja posição se funda sobre uma avaliação neutra de fatos objetivos. Se ele for chamado a influenciar ou até a tomar diretamente decisões políticas (por exemplo, no caso de ser indicado para um cargo de governo), servir-se-á presumidamente de seus conhecimentos científicos, sem seguir motivações partidárias ou ideológicas.

Embora essas análises sejam de 1976 e as afirmações sobre as quais se baseiam datem das décadas de 1960 e 1970, elas parecem incrivelmente atuais se considerarmos alguns acontecimentos recentes (a formação do governo Monti na Itália, por exemplo). Contudo, o que me interessa aqui é menos a aplicação concreta da "ideologia dominante" na Europa atual e antes a concepção de política e de comunidade política que lhe subjaz.

Antes de tudo, devemos constatar que estamos diante de um grave déficit epistemológico: o debate sobre o estatuto das ciências sociais - da discussão sobre o positivismo dos anos de 1960 à discussão metateórica atual, conduzida, entre outros, pelo próprio Boltanski - é simplesmente deixado de lado. No discurso tecnocrático não se coloca em dúvida em momento nenhum se sua própria visão social, econômica e política possui caráter científico (naturalmente, esta não é a posição de todos os cientistas sociais, mas somente dos que defendem o discurso tecnocrático). Isso possibilita que os experts ativos politicamente vejam suas decisões à luz de nexos causais necessários, segundo os 
quais os efeitos almejados deveriam sempre ser alcançados. Ainda mais problemática, do ponto de vista da teoria ou da filosofia política, é a visão social e política que subjaz à "ideologia dominante" dos tecnocratas. Tal visão se fundamenta sobre cinco premissas, todas questionáveis e todas com consequências práticas muito graves.

A primeira premissa consiste em uma visão implicitamente normativa da sociedade, que vê nela um jogo harmônico de interesses diferentes, pois estes nunca chegam (melhor: nunca deveriam chegar) a entrar em conflito. A "ideologia dominante" parte da imagem utópica de uma sociedade pacífica e sem conflito e oferece tal imagem como mera descrição, embora seja evidente que esta implica também uma avaliação positiva. Segundo essa imagem, na sociedade não haveria conflito social se seus membros entendessem a maneira como ela realmente funciona. Se todos dispusessem do saber necessário, aceitariam pacifi158 camente aquilo que lhes aparece como o resultado iníquo de injustiças sociais e de ilegítimas assimetrias de poder. Da ignorância das verdadeiras leis sociais deriva a incapacidade de reconhecer que o desmantelamento das garantias oferecidas pelo Estado no campo social representa um ingrediente necessário do crescimento econômico, ou que a retirada de direitos trabalhistas torna, por um lado, mais precários os empregos, mas, por outro, os asseguram contra a concorrência dos mercados de trabalho estrangeiros etc. Em suma, se os membros da sociedade dispusessem do conhecimento correto das leis que regem a economia e a vida da sociedade, isso eliminaria inúteis tensões sociais e não somente facilitaria a ação dos governos tecnocráticos, mas a tornaria até mais eficiente.

A segunda premissa fundamental é estritamente ligada à primeira e consiste em negar a natureza conflituosa da política. Esta deveria fundar-se no consenso, entendido como condição prévia de qualquer política democrática e 
não como resultado de confrontações e negociações (isto é, como o resultado final da política democrática).

A terceira premissa da "ideologia dominante" concerne à ideia da ação política como exercício de ciência aplicada. Os problemas que a política enfrenta seriam de natureza meramente técnica, cuja solução consistiria na correta aplicação prática do saber especializado fornecido pelas ciências sociais. Correspondentemente, do homem político não se espera que disponha de visões próprias acerca desses problemas e da organização da sociedade, mas que siga as indicações dos experts. Destarte, a política perde o caráter de uma atividade que tem a ver com os desejos, anseios, sonhos e sentimentos das pessoas e se torna antes uma forma aplicada de saber a qual se fundamenta em pressuposições antropológicas. Estas, por sua vez, são bastante problemáticas, pois, a "ideologia dominante" parte da ideia de que é possível identificar fortes regularidades ou até leis do comportamento humano e, nesse sentido, formular prognósticos suficientemente exatos sobre o futuro. Por exemplo, ela parte da ideia de que determinadas medidas tomadas por um governo provocariam automaticamente determinadas consequências nos mercados financeiros internacionais (suscitando a confiança ou a desconfiança dos investidores estrangeiros, favorecendo ou retardando o crescimento econômico etc.). Isso pressupõe uma visão antropológica segundo a qual o ser humano se comporta sempre de maneira racional - no sentido de uma racionalidade econômica -, perseguindo seus interesses e escolhendo sempre as estratégias de ação que os maximizam. Essa visão é aplicada também a macroatores como institutos bancários, empresas, Estados etc. Sem esse pressuposto seria extremamente complicado falar do caráter "científico" de disciplinas como a macroeconomia. Cabe duvidar, contudo, que tal pressuposto seja correto e não faltam estudos que o põem em questão, a partir dos trabalhos clássi- 
cos de Albert Hirschman (2002) até chegar aos estudos mais recentes de Elster (1999a, 1999b), de Sousa (1987), Lakoff (2008) e Green e Shapiro (1994). Mark Taylor avançou a tese sugestiva de que haveria uma relação estrita entre fé religiosa e "racionalidade" econômica, que vai muito além da influência analisada por Weber (2004) do calvinismo sobre o espírito capitalista e que torna a própria economia uma espécie de religião sucedânea (Taylor, 2004). Por fim, vários autores tentam demonstrar com base em dados de pesquisas empíricas que as decisões tomadas nos mercados e na esfera política não são racionais, mas obedecem a fatores emocionais dificilmente previsíveis (Caplan, 2007; Haidt, 2012). Não obstante isso, o discurso dominante afirma que a política deve seguir a lógica dos mercados e tomar medidas racionais, ainda que estas possam causar descontentamento e sofrimento social. A resistência contra tais medidas é representada, então, como irracional e 160 carente de objetividade.

A quarta premissa deriva da terceira e consiste na ideia de que o homem político que toma suas decisões com base no saber especializado dos experts não é responsável pessoalmente por elas, pois são a consequência lógica da aplicação prática de tal saber. Isso significa, em primeiro lugar, a despersonalização da política. O político se torna um simples técnico que reage a fatores externos ao adotar as medidas necessárias. Seu espaço de manobra é extremamente reduzido e seu lugar pode ser tomado, a qualquer momento e sem nenhum problema, por outro técnico - sob condição de que este disponha do mesmo saber que aquele. Isso significa também, em segundo lugar, a definitiva desvinculação entre política e ética. Medidas que resultam em sofrimento evitável socialmente (se políticas diferentes tivessem sido adotadas) são apresentadas como resposta inelutável a problemas que surgem por causa dos mecanismos impessoais da economia. O processo inteiro é descrito como moral- 
mente neutro: os mecanismos em questão obedecem a leis anônimas, representadas como uma espécie de leis naturais. A naturalização da economia (isto é, a ideia de que na esfera da economia tudo acontece de maneira necessária, segundo leis imutáveis e independentemente da vontade dos atores) leva ao mencionado fatalismo, pelo qual os políticos enquanto técnicos se limitam a tomar decisões inevitáveis. A tarefa principal destes passa a ser a de convencer os cidadãos dessa inevitabilidade.

A quinta premissa consiste em aceitar que haverá sempre e inevitavelmente "vítimas do progresso", ou seja, vítimas das leis "férreas" que regem os fatos sociais, em particular os econômicos. Trata-se, em certo sentido, de uma variante do darwinismo social, que condiz particularmente com a naturalização da economia. A exclusão social é vista como o resultado inevitável de uma lei "natural" eticamente neutra e não como o resultado de decisões políticas que poderiam ter sido diferentes. O discurso tecnocrático leva, portanto, a uma forma de fatalismo político e moral, pelo qual a política tem unicamente a tarefa de tornar mais palatável o inevitável e de minimizar suas consequências negativas, sem, porém, poder impedi-las. Em outras palavras, seu espaço de manobra é extremamente reduzido. O discurso tecnocrático representa, portanto, a definitiva naturalização da política e, enfim, da própria vida social. Ele trata os fenômenos como fenômenos naturais e presumidamente os descreve com exatidão, para tirar deles as leis que permitam operar prognósticos certos e ofereçam orientação aos tecnocratas. O Parlamento e os cidadãos servem somente para garantir uma legitimidade formal a decisões que são tomadas acima deles. A própria legitimidade formal é almejada somente por razões de eficácia: decisões formalmente legitimadas por órgãos decisórios democráticos serão mais provavelmente aceitas e obedecidas. 
À visão tecnocrática, que parece prevalecer no momento atual em muitos países industrializados, que está presente também no discurso de alguns políticos brasileiros e na lógica de certas políticas públicas (cujos efeitos são "calculados" estatisticamente como se a realidade social pudesse ser modificada de maneira clara e certa por quem conheça suas leis), se contrapõem vários discursos teóricos. Em seguida, faremos algumas considerações a partir de uma destas teorias: a da democracia radical defendida por Ernesto Laclau e Chantal Mouffe.

\section{Democracia radical}

Essa teoria se caracteriza por questionar diretamente a ideia de que a realidade social obedece a leis imutáveis e é, portanto, planificável. Podemos dizer que seu ponto de partida é o de que o único consenso necessário em uma democracia refere-se à existência de certas regras que impeçam a trans-

162 formação de conflitos de interesse em conflitos armados, que os cidadãos recorram à violência física para implementar suas visões de sociedade. Nesse sentido, a constituição democrática não pressupõe homogeneidade social ou identidade coletiva além daquela criada pela adesão às próprias instituições democráticas ${ }^{9}$. Em outras palavras, os cidadãos de uma democracia não precisam compartilhar entre si interesses materiais ou ideais, valores éticos ou morais, visões do mundo ou da natureza humana. Muito menos estão vinculados aos interesses, valores e visões próprios da geração dos pais constitucionais. A constituição define a arena na qual interesses, valores e visões diferentes ou até opostos podem se enfrentar, sem que isso resulte em conflito aberto ou em guerra civil - exatamente como defendido por Laclau e Mouffe (1985), Laclau (1996) e Mouffe (2000).

\footnotetext{
${ }^{9}$ Nos moldes do patriotismo constitucional defendido, entre outros, por Habermas (2003). A esse respeito, ver também Bunchaft (2011).
} 
Mouffe critica as teorias tradicionais de democracia (inclusive as teorias de democracia deliberativa de cunho rawlsiano e habermasiano) por oferecerem uma imagem negativa do conflito de interesses presente na sociedade e por privilegiarem a racionalidade dos sujeitos, deixando de lado elementos centrais tais como as paixões e os afetos (Mouffe, 2000, p. 95). Essas teorias concebem o indivíduo como "anterior à sociedade, portador de direitos naturais, e como um agente que maximiza sua utilidade ou como um sujeito racional"; assim fazendo, eles desconsideram "relações sociais e de poder, linguagem, cultura e todo o conjunto de práticas que possibilita o fato de tornar-se um agente" (Mouffe, 2000, p. 95). Em outras palavras, desconsideram as condições que permitem a existência de sujeitos concretos em uma sociedade e em uma democracia. Contrariamente a essas teorias, Mouffe insiste na importância das práticas, mais do que dos argumentos: juízos políticos e regras jurídicas são aceitos "porque estão inscritos em formas compartilhadas de vida" e porque há um consenso sobre valores, visões do mundo etc. (Mouffe, 2000, p. 97).

Contudo, contrariamente aos comunitaristas, com os quais ela compartilha a crítica à visão individualista liberal, Mouffe não coloca a ênfase nos traços comuns (valores etc.), mas antes nas diferenças entre distintas visões e interesses. Sua crítica principal ao modelo deliberativo é o fato de esta negligenciar a dimensão do poder ao postular a possibilidade de se chegar livremente a um consenso racional. Segundo Mouffe, as relações assimétricas de poder que caracterizam a vida socioeconômica de uma dada sociedade não podem ser canceladas quando se entra em uma argumentação racional; o "melhor" argumento é reconhecido como tal somente porque naquela sociedade prevalecem determinados valores e determinadas visões que levam a esta conclusão. Mas esses valores e essas visões não são neutros e são, antes, expressão de certa hegemonia ideológica inevitável. A realidade social é constitu- 
ída por relações de poder e é, portanto, sempre de natureza política. "Este ponto de convergência [...] entre objetividade e poder é o que entendemos por "hegemonia" (Mouffe, 2000, p. 99). O poder constitui a própria identidade dos sujeitos sociais e, portanto, não é eliminável. Nas práticas políticas, não há identidades pré-formadas em busca de poder para realizar seus interesses, mas há, antes, "identidades que se constituem de maneira precária e sempre vulnerável” por intermédio de relações de poder (Mouffe, 2000, p. 100). Nesse processo de formação de identidade, os indivíduos se orientam por conceitos e valores que, embora tenham se tornado hegemônicos (o de liberdade individual, por exemplo), eles próprios podem colocar em questão. O caráter democrático de uma sociedade é dado justamente pelo fato de que nenhum ator social pode reclamar para si representar a totalidade da sociedade (Mouffe, 2000, p. 100), como, pelo contrário, acontece quando uma minoria se autoproclama "opinião pública" (como no caso da 164 chamada classe média no Brasil) e pretende impor seus interesses como $o$ interesse geral de toda a sociedade.

As práticas democráticas implicam, portanto, uma luta de poder para estabelecer os valores hegemônicos e/ou para estabelecer as identidades dos sujeitos sociais. A visão agônica de democracia defendida por Mouffe requer que as partes em luta se vejam como adversárias, cujos direitos devem ser respeitados, mas não como inimigos a serem destruídos (como numa visão de mero antagonismo). Tal visão mantém ao mesmo tempo firmemente a ideia de que as práticas políticas são conflituosas e que dizem respeito a relações de poder, a começar pelo poder de certos sujeitos sociais definirem a si mesmos, em vez de terem que aceitar uma definição imposta de fora (por exemplo a de "marginais", de "ralé").

A visão radical de democracia, assim como Laclau e Mouffe a defendem, se opõe, portanto, ao discurso tecnocrático, que quer eliminar de vez a ação política, substituindo-a por uma atividade presumidamente científica de 
administração e de gestão da vida social e econômica de uma dada sociedade, que, por essa perspectiva, deveria ser subtraída à vontade popular, pois esta desconhece as leis objetivas que regram a esfera da economia. Em lugar disso, a teoria da democracia radical reconhece que as práticas democráticas têm como objeto relações de poder, que acabam definindo a identidade dos sujeitos sociais e os valores dominantes em uma sociedade (e, portanto, a "racionalidade" dos argumentos usados nas deliberações públicas).

Em consequência do exposto, podemos formular os seguintes pontos relativos à questão central deste escrito: para que os cidadãos participem ativamente do processo decisório, é necessário mostrar o caráter ideológico (no sentido negativo do termo) do discurso tecnocrático e da correspondente naturalização do status quo. Ao mesmo tempo, é necessário pôr em questão aquelas que são apresentadas como finalidades óbvias, indiscutidas e indiscutíveis da sociedade: crescimento econômico ilimitado, privatização indiscriminada do setor público, incentivos públicos às empresas etc. Pôr em questão não significa aqui negar a importância de tais finalidades, mas repensar suas modalidades, estabelecer novas prioridades ${ }^{10}$. Tudo isso é tarefa de uma crítica social inspirada nos métodos da teoria crítica (como no caso de Boltanski). Naturalmente, esse trabalho de crítica será inútil se não conseguir alcançar a maioria dos cidadãos. Isso pressupõe a existência de uma mídia plural e aberta a todos - uma circunstância praticamente inexistente no Brasil, onde os órgãos de comunicação de massa estão nas mãos de poucos grupos que os usam para perseguir seus interesses econômicos e, portanto, políticos (sem, contudo, admitir isso abertamente $)^{11}$.

\footnotetext{
${ }^{10}$ Exemplos de como repensar as modalidades seriam privilegiar uma distribuição mais justa da riqueza já existente no país, antes de fomentar a produção de nova riqueza destinada a uma minoria; ou ainda, ao fazer privatizações, estabelecer condições favoráveis ao Estado, e não apenas aos sujeitos privados.

${ }^{11}$ Sobre esse ponto, ver Repórteres Sem Fronteiras (2013)
} 
Como se vê, os desafios são muitos e os obstáculos à democratização real (a qual se daria por meio de uma maior participação ativa dos cidadãos no processo decisório) são aparentemente insuperáveis. Os cidadãos têm a percepção de que sua voz não é ouvida e de que seu engajamento não possui relevância nenhuma para influenciar os mecanismos globais e impessoais que dominam suas vidas. Tal percepção está correta à medida que, de fato, a participação se reduz ao voto ou à indignação pública perante os escândalos dos políticos. Dessa forma, os cidadãos preferem se refugiar na esfera privada a qual é garantida por direitos individuais: os sujeitos entendem sua liberdade como mera liberdade jurídica, isolando-se ainda mais do conjunto dos concidadãos e renunciando ainda mais à faculdade de exercer seu poder soberano, o que só pode ser feito conjuntamente a tais concidadãos. Essa contração da participação abre espaço para outros sujeitos, cujo poder e cuja influência nos processos decisórios se 166 tornam cada vez maiores. O discurso tecnocrático e a naturalização do status quo, que se tornaram dominantes, contribuem a desincentivar ainda mais os indivíduos e a suscitar neles a ideia de que a política é um âmbito reservado aos técnicos, no qual não há espaço para novidades e experimentos sociais. Nesse contexto, a participação se limita à escolha de políticos que possuam as qualidades consideradas necessárias para implementar as medidas técnicas inevitáveis. Em tudo isso, a mídia deixa de exercer um papel verdadeiramente crítico e se limita tendenciosamente a defender interesses particulares ou a denunciar políticos em vez de discutir políticas. Perante essa situação, não é fácil pensar em formas de restituir aos cidadãos a confiança em sua capacidade de tomar decisões e de influenciar a realidade, e tampouco era nossa intenção apontar para saídas concretas desse dilema no espaço limitado de um artigo científico. Faz-se mister, contudo, refletir sobre essas questões, se quisermos que nossa sociedade se torne uma sociedade verdadeiramente democrática. 


\section{Alessandro Pinzani}

é professor de filosofia política da UFSC e livre-docente em filosofia pela Universidade de Tübingen.

\section{Referências bibliográficas}

BOLTANSKI L. 2008. Rendre la réalité inacceptable: à propos de "La production de l'idéologie dominante". Paris: Demopolis.

BOURDIEU, P.; BOLTANSKI, L. 1976. "La production de l'ideologie dominante”. Actes de la Recherche en Sciences Sociales, v. 2, n. 3, pp. 4-73.

BUNCHAFT, M. E. 2011. "Algumas críticas à ideia de patriotismo constitucional”. Pensar, v. XVI, pp. 1-10.

CAPLAN, B. 2007. The myth of the rational voter: why democracies choose bad policies. Princeton, NJ: PUP.

CHATTERJEE, P. 2004. The politics of the governed: reflections on popular politics in most of the world. New York: Columbia University Press.

CONDORCET. [no prelo]. Escritos político-constitucionais. Campinas: Ed. da Unicamp.

CROUCH, C. 2004. Post-democracy. Oxford: Polity Press.

DEWEY, J. 1996. Democracy and education: an introduction to the philosophy of education. New York: Free Press.

DOWNS, A. 1999. Uma teoria econômica da democracia. São Paulo: Edusp.

ELSTER, J. 1999a. Strong feelings: emotion, addiction, and human behavior. Cambridge, MA: The MIT Press.

1999b. Alchemies of the mind: rationality and the emotions. Cambridge: CUP.

GREEN, D.; SHAPIRO, I. 1994. Pathologies of rational choice theory: a critique of application in political sciences. New Haven: YUP.

HABERMAS, J. 1973. Kultur und Kritik: Verstreute Aufsätze. Frankfurt am Main: Suhrkamp.

1980. A crise de legitimação no capitalismo tardio. Rio de Janeiro:

Tempo Brasileiro.

2003. Direito e democracia: entre facticidade e validade. Rio de Janeiro: Tempo Brasileiro.

2012. Teoria do agir comunicativo. São Paulo: Martins Fontes.

HAIDT, J. 2012. The righteous mind: Why good people are divided by politics and religion. London: Allen Lane.

HIRSCHMAN, A. 1991. The rhetoric of reaction. Cambridge, MA: Belknap. 2002. As paixões e os interesses: argumentos políticos a favor do capitalismo antes do seu triunfo. Rio de Janeiro: Record. 
HONNETH, A. 2011. Das Recht der Freiheit. Berlin: Suhrkamp.

LACLAU, E.; MOUFFE, C. 1985. Hegemony and socialist strategy: towards a radical democratic politics. London: Verso.

LACLAU, E. 1996. Emancipation(s). London: Verso.

LAKOFF, G. 2008. The political mind: why you can't understand 21st-century American politics with an 18th-century brain. New York: Viking.

LUHMANN, N. 1983. Legitimation durch Verfahren. Frankfurt am Main: Suhrkamp.

MAUS, I. 2011. Über Volkssouveränität: Elemente einer Demokratietheorie. Berlin: Suhrkamp.

MOUFFE, C. 2000. The democratic paradox. London: Verso.

OFFE, C. 1984. Problemas estruturais do estado capitalista. Rio de Janeiro: Tempo Brasileiro.

PINZANI, A. 2005. "Gobierno de las leyes y/o gobierno de los ciudadanos. ¿Hay compatibilidad entre republicanismo y democracia liberal?”. Isegoria, v. 33, pp. 77-97.

2006. "Os demônios e as facções. Kant e Madison sobre paixões e instituições”. Crítica, v. 11, n. 33, pp. 131-152.

RANCIÈRE, J. 2005. La haine de la démocratie. Paris: La fabrique.

REPÓRTERES SEM FRONTEIRAS. 2013. "Relatório sobre liberdade de imprensa no Brasil”. Disponível em http://en.rsf.org/IMG/pdf/brazil_report.pdf. Acesso em 16/02/2013.

ROSANVALLON, P. 2006. La contre-democrátie : la politique à l'âge de la défiance. Paris: Seuil.

SCHUMPETER, J. A. 1984. Capitalismo, socialismo e democracia. Rio de Janeiro: Jorge Zahar.

SIEYÈS, E. 2003. ¿Qué es el terceiro estado? Ensayo sobre los privilegios. Madrid: Alianza Editorial.

SOUSA, R. 1987. The rationality of emotion. Cambridge, MA: The MIT Press.

TAYLOR, M. C. 2004. Confidence games: money and markets in a world without redemption. Chicago: The University of Chicago Press.

WEBER, M. 2004. A ética protestante e o espirito do capitalismo. São Paulo: Companhia das Letras.

ŽIŽEK, S. 2008. A visão em paralaxe. São Paulo: Boitempo. 


\section{DEMOCRACIA VERSUS TECNOCRACIA: APATIA E PARTICIPAÇÃO EM SOCIEDADES COMPLEXAS}

\section{ALESSANDRO PINZANI}

Resumo: Discutimos no presente artigo a questão da apatia política em nossas democracias não do ponto de vista empírico, mas por meio da análise de vários discursos e modelos teóricos que resultam ser, respectivamente, "dominantes" e "antagônicos" tanto na academia quanto na própria esfera pública. A primeira oposição analisada é aquela entre o modelo constitucionalista da democracia e o modelo da soberania popular. A partir dessa análise, passamos à discussão dos fenômenos sociais de judicialização e de indignação por parte dos cidadãos. Indignação esta, que, por sua vez, se opõe ao ativismo positivo de quem está disposto a participar diretamente do processo decisório, inclusive em formas não institucionalizadas de participação. Por fim, analisamos a oposição entre o discurso tecnocrático, caracterizado pela ênfase no consenso sobre leis socioeconômicas presumidamente formuláveis de maneira científica, e a ideia de uma democracia radical, caracterizada por uma visão de "agonismo" democrático.

Palavras-chave: Democracia Radical; Tecnocracia; Apatia Política; Constitucionalismo; Soberania Popular.

\section{DEMOCRACY VERSUS TECHNOCRACY: APATHY AND PARTICIPATION IN COMIPLEX SOCIETIES}

Abstract: We discuss in this article the topic of political apathy in our democracy; it does it not from an empirical perspective, but through an analysis of several discourses and theoretical models, which are considered to be, alternately, "dominant" or "antagonist" both in academy and in public sphere. The first opposition to be analyzed is that between constitutionalist model and popular sovereignty model. From this analysis, we start the discussion about the social phenomena of judicialization and of indignation among citizens, 
which stands opposite to the positive activism of those, who are willing to participate directly in decisional processes, including through not institutionalized forms of participation. Finally, we analyze the opposition between technocratic discourse and the idea of a radical democracy, with its vision of a democratic "agonism". Keywords: Radical Democracy; Technocracy; Political Apathy; Constitutionalism; Popular Sovereignty. 